\title{
Experimental Comparison of Designed Inductance Coils for Wireless Power Transfer
}

\author{
Viktor Shevchenko* (Ph. D. Student, Chernihiv National University of Technology, Chernihiv, Ukraine), \\ Maksym Khomenko (Senior Researcher, Chernihiv National University of Technology, Chernihiv, Ukraine), \\ Igor Kondratenko (Principal Researcher, Institute of Electrodynamics of National Academy of Sciences of Ukraine, \\ Kyiv, Ukraine), \\ Oleksandr Husev (Leading Researcher, Chernihiv National University of Technology, Chernihiv, Ukraine), \\ Bohdan Pakhaliuk (Ph. D. Student, Chernihiv National University of Technology, Chernihiv, Ukraine)
}

\begin{abstract}
The paper is devoted to the comparison of different types and different values of coils for inductive power transfer in the classical circuit. This topic is relevant with the growing demand and interest in wireless chargers and the diversity of inductance coils for wireless power transfer. The main geometric parameters affecting the coil efficiency are determined. For experimental verification the classical scheme for wireless power transfer is used based on a full-bridge inverter. Different coils at different distance between them, lateral misalignment and load resistance changed are tested. It is determined that single-layer coils have better transmit-receive efficiency than double-layer ones, especially with series-series compensation topology. The application of two-layer coils is recommended in case of high input current. The investigated samples have efficiency at the level of industrial standards. The design approach can be used for any level of power and application, including wireless charging of electric vehicle batteries.
\end{abstract}

Keywords - AC-DC power converters electromagnetic coupling; Finite element modelling; Inductive power transmission; Wireless power transfer.

\section{INTRODUCTION}

The electromagnetic system is a very important part of Wireless Power Transfer (WPT) devices, and it makes a major contribution to the efficiency of the entire system. The electromagnetic system consists of transmitter and receiver coils that are separated by a non-magnetic gap.

The overall efficiency of the WPT device and the efficiency of energy transmission and receiving are determined by the ratios of different geometric parameters [1]-[3]. In addition to the geometric parameters of the coil, efficiency is also determined by its design, namely, the number of layers, the cross-section of wires, etc. The efficiency of inductors, connected through a non-magnetic interval, is mainly determined by the product of the magnetic coupling coefficient $(k)$ and the quality factor $(Q)[1]$.

The inner and outer radii of the circular coil mainly determine the coupling coefficient [1], [2]. For a given outer radius, a smaller inner radius always leads to an increase in magnetic coupling. However, when the inner radius reaches about half the outer radius, an additional increase in the coupling coefficient becomes insignificant [2]. The wire diameter and the distance between the turns do not have a significant effect on the coupling factor. The optimization calculations in [2] also determined that the number of the primary turns and the ratio of the number of the primary turns to that of the secondary turns also have a slight influence on the coupling coefficient. On the other hand, increasing the number of turns and placing the winding in one layer increases the coupling between the coils of the primary and secondary coils, which increases the quality factor and the coupling coefficient [3].

The coil inductance is directly proportional to the square of the number of turns. The coil resistance is directly proportional to the number of turns. An increase in the number of turns leads to an increase in the inductance and quality factor, while the active resistance increases less intensively [3]. A balance must be found between the wire diameter and the number of turns to obtain optimum inductance.

The active resistance (ESR) of the coil due to the skin effect at high frequencies may differ from the active resistance with only DC current. To reduce the active resistance of the alternating current, a litz wire is used [1], [4].

In addition, it should be noted that in order to implement an efficient WPT system, it is necessary to use the reactive power compensation caused by the presence of inductance [5]. According to sources, the efficiency of WPT without compensation does not exceed $50 \%$ [6].

The main aim of the article is to investigate and compare coils with different inductance as part of WPT system at different reactive power compensation schemes.

\section{CASE STUdy: SYSTEM DESCRIPTION}

The research of the classical WPT scheme [7], [8] is presented for different coil types and compensation topologies (Fig. 1). The primary (transmitting) part of classical WPT scheme consists of a full-bridge inverter, a primary series

\footnotetext{
* Corresponding author.

E-mail: shevaip1990@gmail.com
} 
compensation capacitor $C_{\text {prim }}$ and an inductance $L_{\text {prim. A }}$ secondary (receiving) part contains a secondary series $C_{\text {sec-ser }}$ or a parallel $C_{\text {sec-par }}$ compensation capacitor and an inductance $L_{\mathrm{sec}}$, a passive diode bridge rectifier, an output filter $C_{\mathrm{f}}$ and a load resistance $R_{\mathrm{L}}$. Experimental tests were conducted in open-loop mode at a frequency of $100 \mathrm{kHz}$.

There are several options for implementing reactive power compensation in a WPT system [5], [9]. The difference is a series or parallel placing of the capacitor relative to the inductor. In all circuits, the capacitor is calculated so that the switching frequency of the transistors is close to the resonance frequency of the LC link. There are four basic compensation topologies on the basis of which the vast majority of semiconductor structures are built: series-series (SS), seriesparallel (SP), parallel-serial (PS) and parallel-parallel (PP). Analysing the application of existing topologies, it was found that the most common were serial-serial and serial-parallel topology [2], [5], [9]-[11].

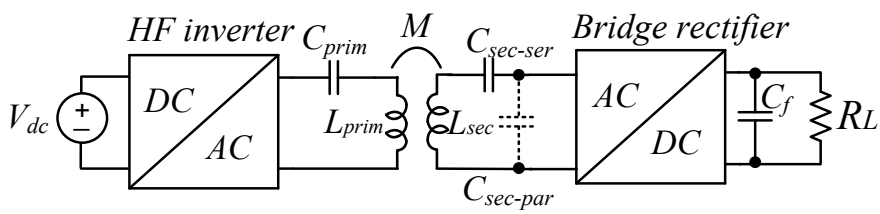

Fig. 1. Classical WPT circuit.

Due to the complexity of analytical calculations [12], the mathematical package "ANSYS Electromagnetics Suite" was used to determine the parameters of the inductors and the phenomenon of mutual induction [13]. The calculations were performed using the Finite Element Modelling method (FEM) [14].

\section{RESULTS OF EXPERIMENTS AND SIMULATIONS}

A vast majority of commercial wireless solutions have a power less than 20 watts. In most cases of such solutions, the intermediate step-down transformer is utilised. Otherwise, a much larger self-inductance of the coil is required on the transmitting side [2]. Devices with higher power levels are at the stage of research and commercialization.

In the previous paper [15], different types of inductors for wireless power transmission were analysed. As a result, the shape of circular coils was chosen. Previous simulation results of the whole WPT system operation with such inductances were carried out in the PSIM Simulation program and covered in previous work [15]. The experiment was conducted with handmade circular coils of $65 \mu \mathrm{H}$ and $10 \mu \mathrm{H}$ (Fig. 2c). Also, for experimental comparison, the previously developed and modelled inductors were taken with inductance $5.8 \mu \mathrm{H}, 65 \mu \mathrm{H}$, $10 \mu \mathrm{H}$ (Table I). Each coil is mounted on a ferrite plate, which increases the coupling coefficient $\mathrm{k}$ between the coils and shields their electromagnetic field outside the working space. All coils have similar geometric dimensions. Different inductance value is realized due to the different number of turns and the diameter of the wire. The first coil $(5.8 \mu \mathrm{H})$ has a double wire winding, which is enclosed in two layers: one above the other as shown in Fig. 2c. Double coils of wire are connected in parallel at each of the terminals of the coil. Coil parameter simulation and experimental inductance testing were performed at $100 \mathrm{kHz}$.

TABLE I

PARAMETERS OF THE PREVIOUSLY DEVELOPED AND MODELLED INDUCTORS

\begin{tabular}{|c|c|c|c|}
\hline Description of parameter & \multicolumn{3}{|c|}{ Nominal parameters for coil } \\
\hline Inductance value & $5.8 \mu \mathrm{H}$ & $10 \mu \mathrm{H}$ & $65 \mu \mathrm{H}$ \\
\hline Outer diameter of coil, mm & 50 & 51 & 52 \\
\hline Inner diameter of coil, mm & \multicolumn{3}{|c|}{20} \\
\hline Wire diameter, mm & 1.4 & 1.2 & 0.48 \\
\hline $\begin{array}{c}\text { Length and width of the } \\
\text { ferrite core with height, mm }\end{array}$ & \multicolumn{3}{|c|}{$53 \times 53 \times 2.5$} \\
\hline $\begin{array}{c}\text { Structure of layers } \\
\text { Relative magnetic } \\
\text { permeability of ferrite }\end{array}$ & double & single & single \\
\hline Number of turns & $\begin{array}{c}10 \\
\text { (double) }\end{array}$ & 12 & 30 \\
\hline Coil resistance, $\Omega$ & 0.004 & 0.0013 & 0.5 \\
\hline
\end{tabular}

Figure 2 shows the experimental WPT system (Fig. 2a), tested coils (Fig. 2b) and a double-layer coil 3D model (Fig. 2c). The experimental WPT system was assembled in a power electronic laboratory. It has STM32 Nucleo-64 development board (NUCLEO-F303RE) (1), a primary side PCB (2), a coil positioning system (3), a secondary side PCB (4), an electronic dc load (5). The primary side PCB contains switching transistors with drivers that are controlled by the development board. The transmitter coil is placed on the bottom side while the receiver coil (movable) is placed on the top side.

The WPT system efficiency was determined without considering the actual power losses in the control system. The output power was displayed on the electronic load screen. Input power was determined by measuring the input voltage and current with multimeters. The temperature of the circuit elements was also measured with a thermal camera. The highest temperature was $64{ }^{\circ} \mathrm{C}$ in the transistor driver power circuits at 2.5 A input current.

\section{A. Experimental and Simulation Dependencies from Load Resistance at Different Input Voltage Levels}

Experiment number 1 (exp. 1) was made with two coils $5.8 \mu \mathrm{H}$ and SS compensation circuit; experiment number 2 (exp. 2) was made with two coils $65 \mu \mathrm{H}$ and SS compensation; experiment number 3 (exp. 3) was made with transmitter coil $65 \mu \mathrm{H}$ and receiver $10 \mu \mathrm{H}$ and SS compensation; experiment number 4 (exp. 4) was made with transmitter coil $65 \mu \mathrm{H}$ and receiver $10 \mu \mathrm{H}$ and SP compensation circuit.

Figure 3 shows experimental and simulation dependencies with output power $\left(P_{\text {out }}\right)$ and efficiency $(E)$ from load resistance $\left(R_{\text {load }}\right)$ at different input voltage levels and gap between coils $(\delta)$ $\delta=1 \mathrm{~mm}$. Some waveforms for those experiments are shown in Fig. 5. 


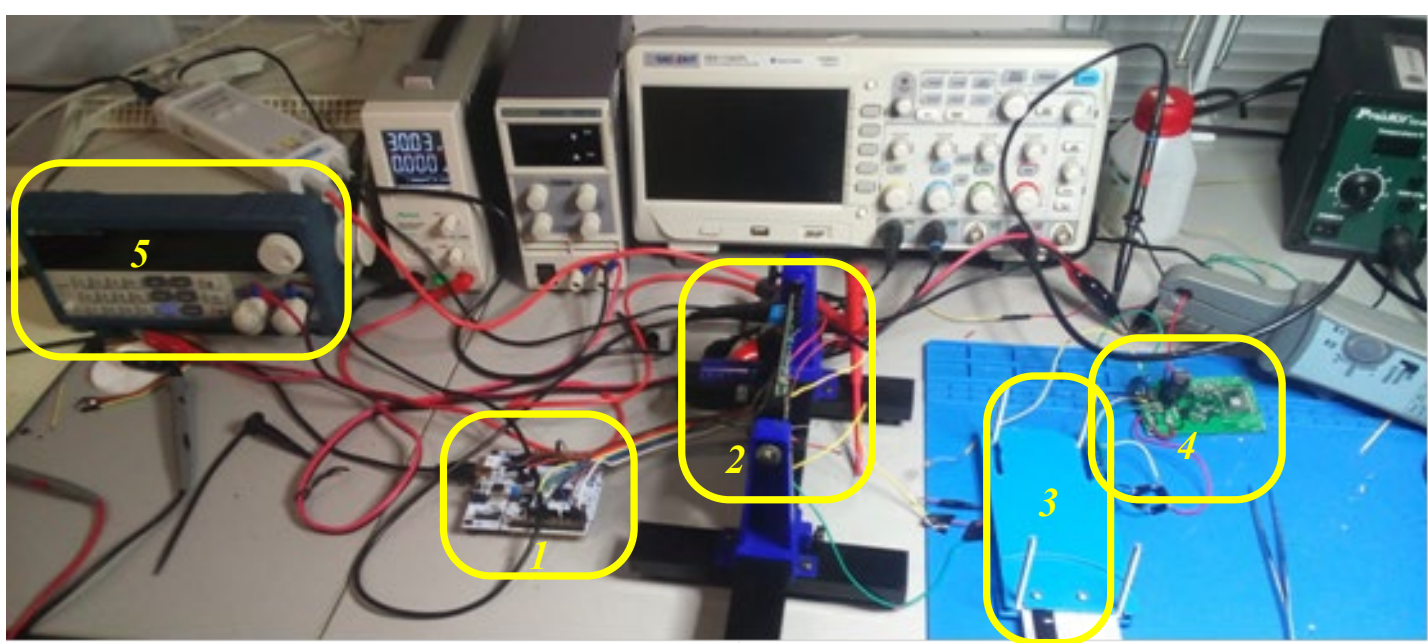

a)

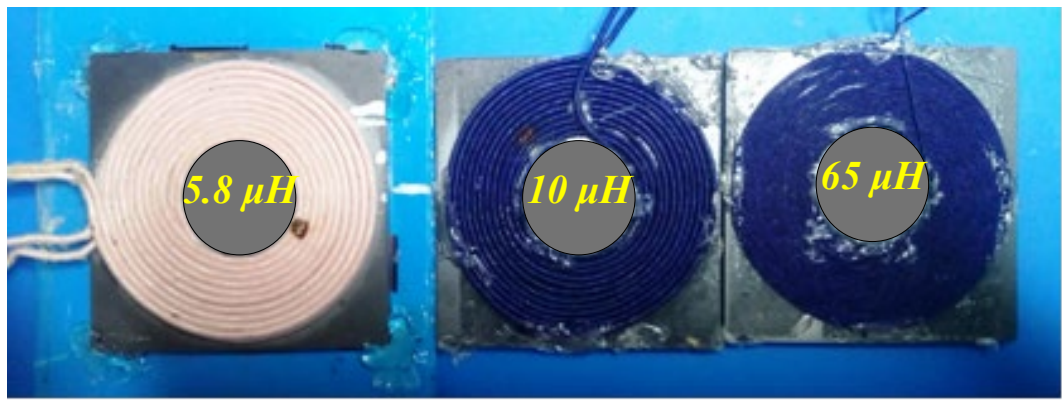

b)

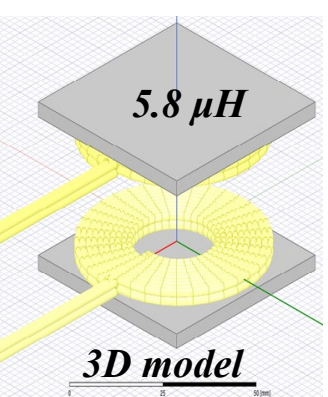

c)

Fig. 2. Investigating WPT system and designed coils: a) experimental laboratory WPT system; b) tested coils; c) double-layer coil 3D model.

Results for experiment number 1 are shown in Fig. 3a-b. For each load value, the pulse rate of the inverter was selected to obtain the maximum output power. The graph of power change at $V_{\text {in }}=10 \mathrm{~V}$ differs from other curves. In Fig. 3a, there is the highest output power. In addition, the highest input voltage corresponds to the best efficiency values for all load points (Fig. 3b). It should be noted that experimental investigations show that for each value of the input voltage there is an optimal value of the load at which the maximum output power and efficiency can be achieved.

For experiment 2 at SS compensation results are shown in Fig. 3c-d. Two $65 \mu \mathrm{H}$ coils deliver lower power at higher input voltages than those with less self-inductance coils (Fig. 3c). It can be concluded that the higher the inductance of the coils, the lower the output current and power will be when the output voltage level is increased. As the input voltage decreases, efficiency also decreases (Fig. 3d). However, the absolute values of efficiency are higher than in the previous experiment.

It can be concluded that the use of coils with an inductance of $5.8 \mu \mathrm{H}$ is more appropriate at low input voltages and high current. This is embedded in geometry (double coils of wire of sufficiently large diameter with relatively small inductance).

Results for experiment number 3 are shown in Fig. 3e-f. This experiment was performed at SS compensation but with different inductances on the primary and secondary sides
(Fig. 3e). The transmitted power is approximately the same value as in the case of exp. 2 (Fig. 3c). However, the receiving coil has an inductance of $10 \mu \mathrm{H}$, and it can accept more power than transmitted in this case. The efficiency is slightly lower (Fig. 3f) than for the case of two $65 \mu \mathrm{H}$ coils.

For experiment 4 at SP compensation results are shown in Fig. $3 \mathrm{~g}-\mathrm{j}$. It is known that in order to work effectively with a SP compensation scheme, it is necessary to adjust the resonant circuit of the transmission part when changing the coupling coefficient $\mathrm{k}$ between the receiving and transmitting coils [9]. Analytically this will be defined as follows:

$$
C_{\text {prim }}=\frac{1}{L_{\text {prim }}\left(1-k^{2}\right) \cdot \omega_{\text {res }}^{2}} \text {. }
$$

According to the previous experiments, the dependences of the output power and the efficiency as a function of the load are shown in Fig. $3 \mathrm{~g}$ and Fig. $3 \mathrm{~h}$. The receiving coil has an inductance of $10 \mu \mathrm{H}$, the transmitting coil is $65 \mu \mathrm{H}$. Unlike SS compensation, maximum power is achieved with relatively low load resistance. All values are obtained at the maximum achievable coupling coefficient $k=0.95$.

Fig. $3 \mathrm{i}$ and Fig. $3 \mathrm{j}$ show similar results, but with different values of the coupling coefficient. It can be seen that at $k=0.8$, both maximum power and efficiency are significantly reduced. 
It should be noted that the decrease in efficiency and power occurs despite the fact that the capacity in the transmission
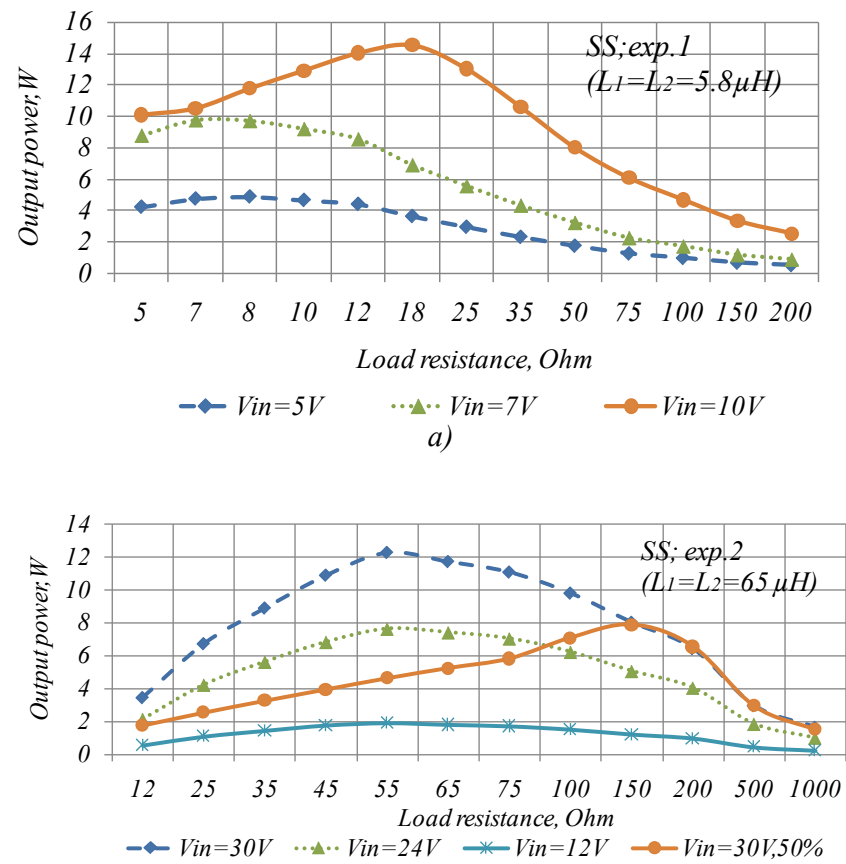

c)

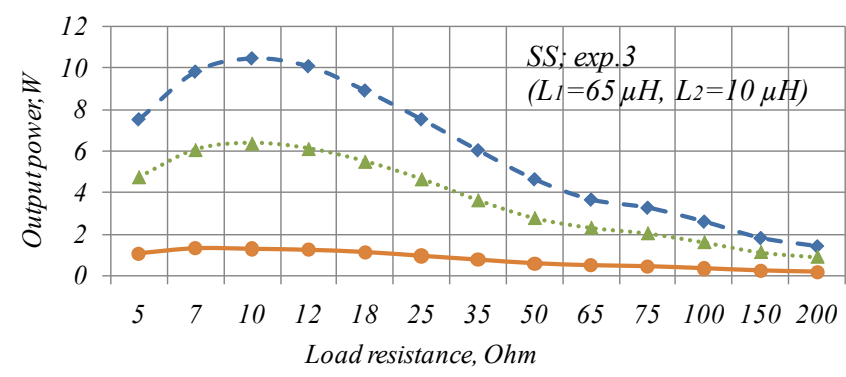

$\multimap$ Vin $=30 \mathrm{~V} \quad \cdots \cdot \cdot \mathrm{Vin}=24 \mathrm{~V} \quad \longrightarrow$ Vin $=12 \mathrm{~V}$

e)

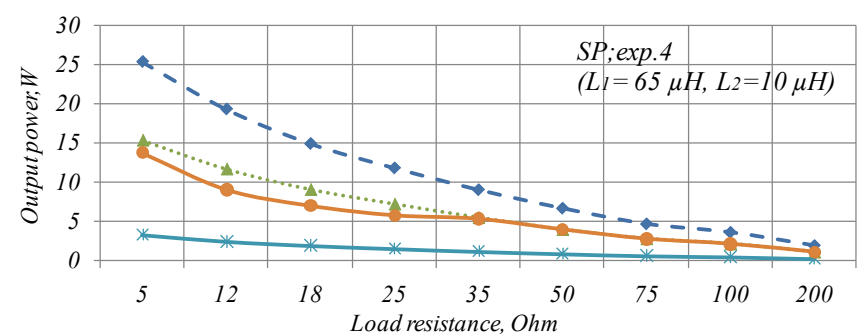

$-\leftarrow$ Vin $=30 \mathrm{~V}, k=0.95$

g) $\quad \cdots \cdot \operatorname{Vin}=24 V, k=0.95$ circuit also changes in accordance with Eq. (1). These results were confirmed by the simulation results.
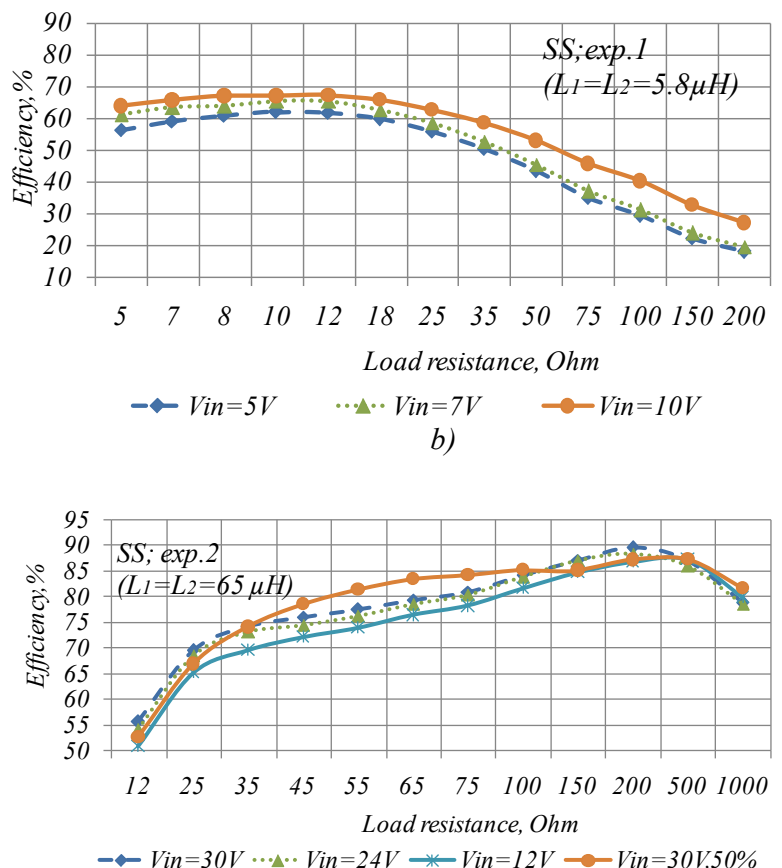

d)
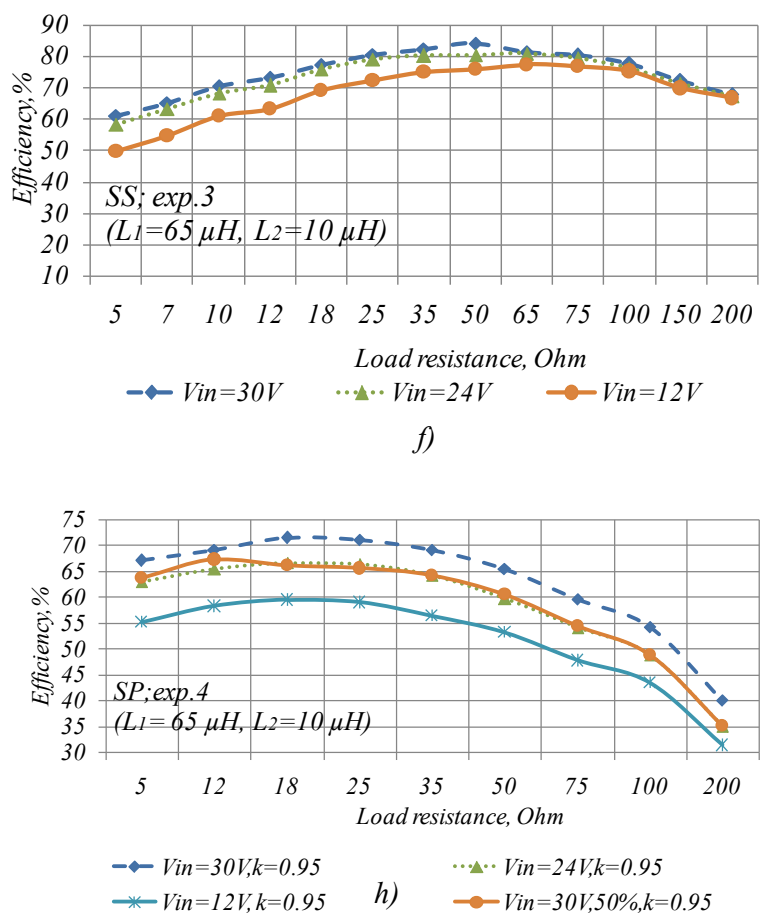


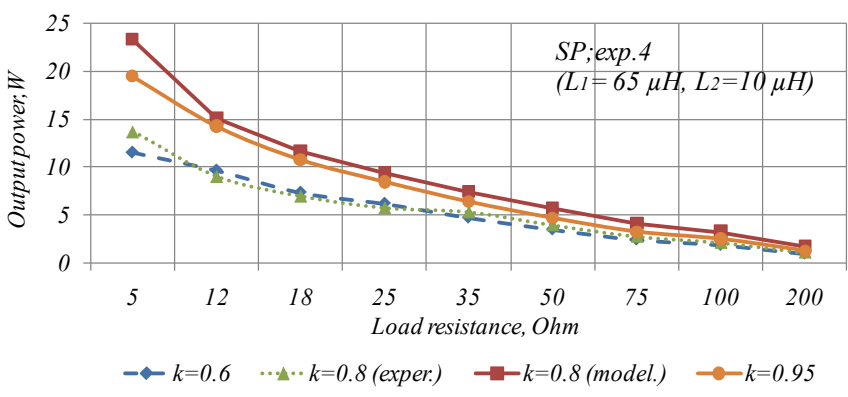

i)

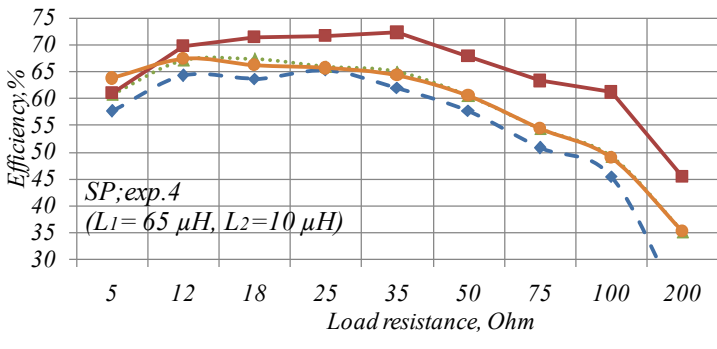

$\multimap-0.6 \cdots \cdots \cdot k=0.8$ (exper) $\rightarrow-k=0.8$ (model.) $\multimap-k=0.95$

j)

Fig. 3. Experimental and simulation dependences with output power (on the left) and efficiency (on the right) from load resistance $\left(R_{\text {load }}\right)$ at different input voltage levels and at gap between coils $\delta=1 \mathrm{~mm}$ for the investigated compensations of topology.

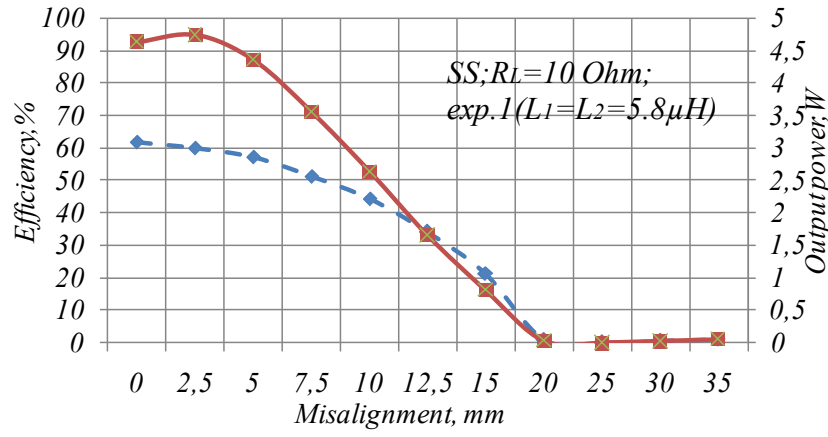

$-ヶ$ efficiency $\rightarrow$ outputpower

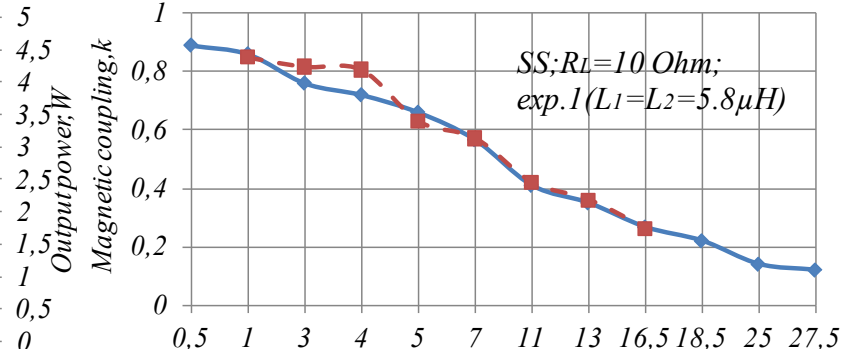

Distance between coils $\delta$, ( $\mathrm{mm}$ )

$\multimap$ airgap,model. b) ${ }^{-}-$airgap,experiment

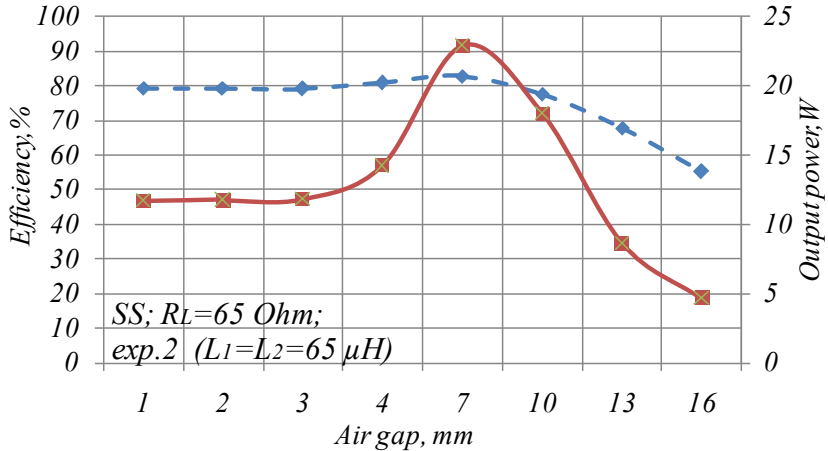

$-\bullet$ efficiency c) $\quad \varangle-$ outputpower

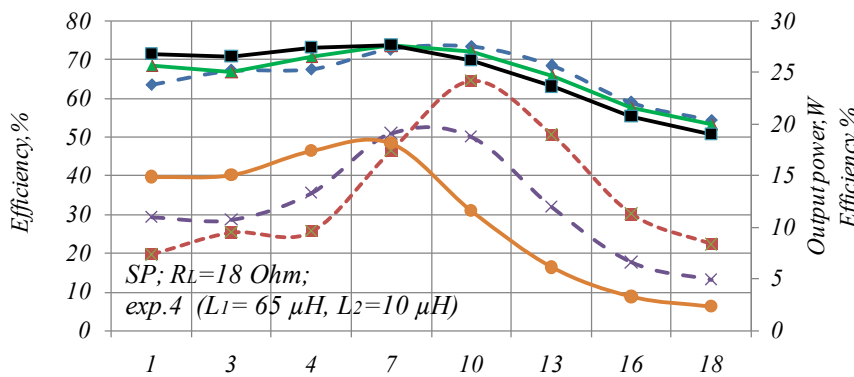

Air gap, mm

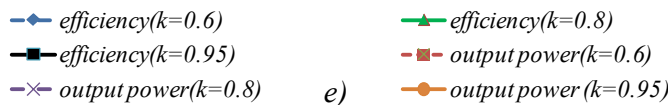

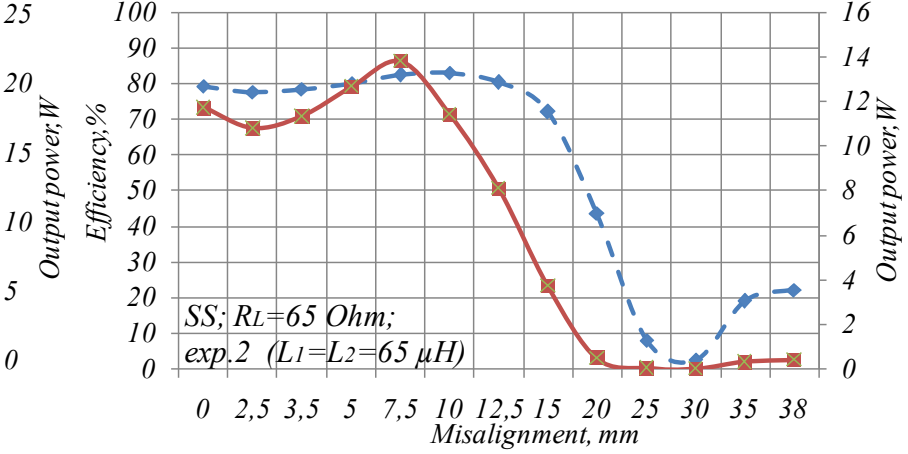

$-\diamond$ efficiency d) $\quad-$ outputpower

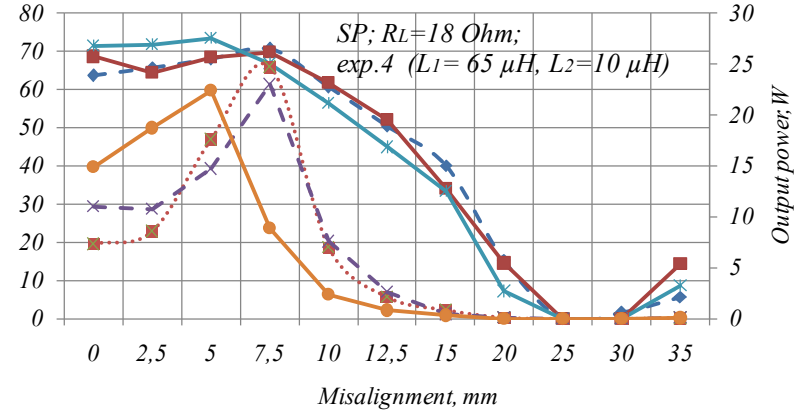

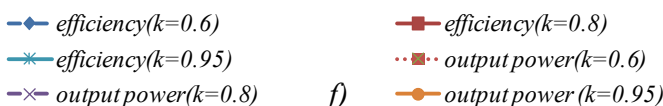

Fig. 4. Simulation and experimental dependences of efficiency and output power from changing the air gap (b, c, e) and lateral misalignment (a, d, f) between coils. 


\section{B. Experimental and Simulation Dependences from Changing the Air Gap and Lateral Misalignment between Coils}

A series of follow-up experiments was conducted to investigate the effect of the coupling coefficient on the performance of the WPT in more detail. Figure 4 shows simulation and experimental dependences efficiency and output power from changing the air gap $(\delta)$ and lateral misalignment $(\Delta)$ between coils. For experiments $V_{\text {in }}=30 \mathrm{~V}$ (for Fig. $4 \mathrm{a}-\mathrm{b}$, $\left.V_{\text {in }}=5 \mathrm{~V}\right), \delta=1 \mathrm{~mm}$. Diagrams are shown for optimum point for each experiment. For experiment 1 this is $10 \Omega$ (Fig. $4 \mathrm{a}-\mathrm{b}$ ); for exp. $2 R_{\text {load }}=65 \Omega \quad$ (Fig. 4c-d); for exp. $4 \quad$ (SP compensation) $R_{\text {load }}=18 \Omega$ (last two diagrams).

To compare the experimental curve of the coupling coefficient depending on the distance between the coils with the simulation data, the coupling coefficient was determined. According to the known method, coils are fixed at a certain distance. The self-inductances $\left(L_{1}\right.$ and $\left.L_{2}\right)$ and the inductance of the series connected coils are measured $\left(L_{12}\right)$. As a result, the following value of the mutual inductance $M$ is calculated by (2):

$$
M=\frac{1}{2}\left(L_{12}-L_{1}-L_{2}\right) \text {. }
$$

According to the known Eq. (3) [16], the coupling coefficient can be determined:

$$
k=\frac{M}{\sqrt{L_{1} \cdot L_{2}}} .
$$

In the first experiment (exp. 1), the high coupling coefficient was observed due to the short distance. With increasing distance there was a decrease in the coupling coefficient (Fig. 4b). The results of simulation and experiment are almost identical, which indicates the correctness of the coil model.

According to the SS topology properties, the efficiency of energy transfer at changing distance between the coils over a wide range is acceptable and is kept at a relatively high level (Fig. $4 \mathrm{c}-\mathrm{d}$ ). The point of approaching the curves to zero in Fig. $4 \mathrm{~d}$ for experiment 2 indicates that $50 \%$ of the secondary coil overlap is reached. With further misalignment, energy begins to transfer again in small quantities due to the interaction between the outer coils of the primary and secondary coils.

Theoretically, the maximum power and efficiency for SP compensation at $k \approx 0.95$ coupling is expected at zero misalignment, since the capacitor is calculated for this value. However, the maximum was observed at the distance of 3-4 mm air gap (Fig. 4e-f). For other couplings, the behaviour of the curves according to the theory is as follows: if the capacitors are designed for weaker coupling, then the distance at which the maximum output power and efficiency are reached will be greater. This deviation can be explained by the difference in the outer diameters of the coils (up to 1-2 $\mathrm{mm}$ ) and some displacement of the coils from the centre of ferrite for the handmade coils.
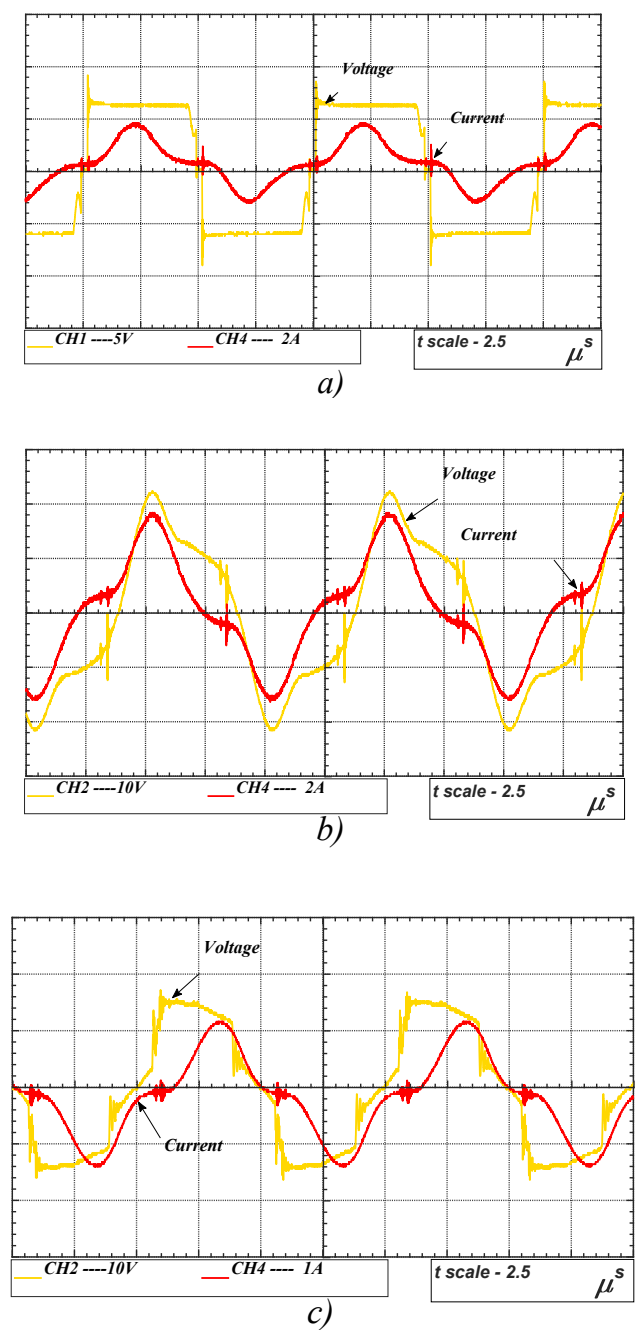

Fig. 5. Waveforms at a distance of $1 \mathrm{~mm}$ between coils: a) output voltage of the inverter $\left(V_{\text {inv }}\right)$ and the current on the primary side $\left.\left(I_{\text {prim }}\right) ; \mathrm{b}, \mathrm{c}\right)$ voltage $\left(V_{\text {sec }}\right)$ and the current on the secondary side $\left(I_{\mathrm{sec}}\right)$ (after the secondary capacitor before the diode bridge)

Waveforms at a distance of $1 \mathrm{~mm}$ coils are shown in Fig. 5. Figure 5a shows the output voltage of the inverter $\left(V_{\text {inv }}\right)$ and the current on the primary side $\left(I_{\text {prim }}\right)$. Figures $5 \mathrm{~b}$ and $5 \mathrm{c}$ represent the voltage $\left(V_{\mathrm{sec}}\right)$ and the current on the secondary side $\left(I_{\mathrm{sec}}\right)$ (after the secondary capacitor before the diode bridge). For Fig. $5 \mathrm{a}-\mathrm{b} \quad V_{\text {in }}=30 \mathrm{~V}, R_{\mathrm{L}}=18 \Omega, k=0.95$ at exp. 4 (SP compensation). For the last figure $V_{\text {in }}=7 \mathrm{~V}, R_{\mathrm{L}}=25 \Omega, k=0.85$ for exp. 1 (SS compensation).

It should be noted that due to the resonance processes, the current through the coils is close to sinusoidal. Also, common mode current and voltage signals on the primary and secondary side indicate the absence of a reactive component, and therefore the correctness of the calculation of the resonant circuit. In all cases, at a distance of $1 \mathrm{~mm}$ between the coils, the signals on the primary side had a similar shape. The absence of highfrequency harmonics in the form of current and the use of the litz wire allow reducing the skin effect and focusing on the calculated active resistance as the only source of energy loss in 
inductors. Table II summarises the main points of study of different coils at different compensation topologies.

TABLE II

COMPARISON OF THE MAIN RESULTS OF EXPERIMENT

\begin{tabular}{|c|c|c|c|c|}
\hline Parameters & \multicolumn{4}{|c|}{ Values } \\
\hline $\begin{array}{c}\text { Number of } \\
\text { experiment }\end{array}$ & Exp. 1 & Exp. 2 & Exp. 3 & Exp. 4 \\
\hline $\begin{array}{c}\text { Type of } \\
\text { compensation }\end{array}$ & SS & SS & SS & SP \\
\hline $\begin{array}{c}\text { Pair of coils } \\
\text { Two 5.8 } \\
\mu \mathrm{H}\end{array}$ & $\begin{array}{c}\text { Two } 65 \\
\mu \mathrm{H}\end{array}$ & $\begin{array}{c}65 \mu \mathrm{H} \text { and } \\
10 \mu \mathrm{H}\end{array}$ & $\begin{array}{c}65 \mu \mathrm{H} \text { and } \\
10 \mu \mathrm{H}\end{array}$ \\
\hline $\begin{array}{c}\text { Maximum } \\
\text { efficiency }\end{array}$ & $68 \%$ & $88 \%$ & $85 \%$ & $74 \%$ \\
\hline $\begin{array}{c}\text { Maximum } \\
\text { achieved output } \\
\text { power at load } \\
\text { variable, W }\end{array}$ & $\begin{array}{c}14.5(\mathrm{at} \\
\left.V_{\text {in }}=7 \mathrm{~V}\right)\end{array}$ & $\begin{array}{c}12(\mathrm{at} \\
\left.V_{\text {in }}=30 \mathrm{~V}\right)\end{array}$ & $\begin{array}{c}10.4(\mathrm{at} \\
\left.V_{\text {in }}=30 \mathrm{~V}\right)\end{array}$ & $\begin{array}{c}25(\mathrm{at} \\
\left.V_{\text {in }}=30 \mathrm{~V}\right)\end{array}$ \\
\hline $\begin{array}{c}\text { Optimum point at } \\
\text { load resistance, } \\
\text { Ohm }\end{array}$ & 10 & 65 & 25 & 18 \\
\hline $\begin{array}{c}\text { Coupling } \\
\text { coefficient at air } \\
\text { gap 1 mm }\end{array}$ & 0.85 & $\begin{array}{c}\text { Not } \\
\text { measured }\end{array}$ & 0.95 & 0.95 \\
\hline
\end{tabular}

The relatively low efficiency of the coil of $5.8 \mu \mathrm{H}$ in the experiments can be explained by a lower coupling coefficient $(k=0.85$ for an air gap of $1 \mathrm{~mm})$ compared to the other coils under investigations. This fact is confirmed by modelling and experimental measurement of mutual inductances with next calculation. This is also confirmation that single-layer coils are more efficient than double-layer coils. In the case of a singlelayer coil, all coils are in the same plane, which increases the coupling coefficient between such coils. In double-layer structure, the transmission power can be increased by reducing active resistance. At the same time, the coupling coefficient and partially the quality factor are reduced (due to fewer turns). Therefore, the coil efficiency will be less. It is also worth noting that lower inductance of the coil corresponds to higher current oscillation, which in turn leads to the increased conduction losses.

The obtained results of energy transfer efficiency are close to the conventional solutions with similar parameters [17]-[19].

\section{CONCLUSIONS}

The complex research has been conducted, namely, a combination of modelling and experimentation on WPT. As a result, the efficiency of energy transfer at different values of inductance and compensation schemes was determined. More than $80 \%$ energy transfer efficiency was achieved. This is the level of industrial samples.

All inductors had similar geometric dimensions. In this case, double-layer coils have some advantages and are recommended for use in the case of relatively high currents and low voltages. However, in most cases, they will be less efficient than singlelayer coils. This is because the decrease in active resistance does not compensate for the significant decrease in the inductance and the coupling coefficient between such coils.

Single coils with different inductance values will be more effective with SS compensation, higher input voltage and less current (higher output load resistance). Two identical $65 \mu \mathrm{H}$ inductors provide high efficiency over a wide range of coupling and load changes due to SS topology properties. High efficiency and transmit power are achieved by SP compensation for certain coupling factors for which the primary compensating capacitor is calculated. Therefore, SP compensation can be successfully used at a fixed distance between coils at low load resistance.

The results of investigation can be also generalized to any power level, in particular wireless battery charging systems. At higher power levels, the size of coils is increasing correspondently in order to provide acceptable conduction losses and coupling coefficient.

\section{ACKNOWLEDGMENT}

The present research has been supported by the Ukrainian Ministry of Education and Science (Grants No. 0117U007260 and No. 0118U003865) and Ukrainian-Latvian project (Grant No. 0119U102105).

\section{REFERENCES}

[1] D. Patil, M. K. McDonough, J. M. Miller, B. Fahimi and P. T. Balsara, "Wireless Power Transfer for Vehicular Applications: Overview and Challenges," in IEEE Transactions on Transportation Electrification, vol. 4, no. 1, pp. 3-37, March 2018. https://doi.org/10.1109/TTE.2017.2780627

[2] R. Bosshard, J. W. Kolar, J. Mühlethaler, I. Stevanović, B. Wunsch and F. Canales, "Modeling and $\eta$ - $\alpha$-Pareto Optimization of Inductive Power Transfer Coils for Electric Vehicles," in IEEE Journal of Emerging and Selected Topics in Power Electronics, vol. 3, no. 1, pp. 50-64, March 2015. https://doi.org/10.1109/JESTPE.2014.2311302

[3] R. Bosshard, J. M $\mu$ Hlethaler, J. W. Kolar, and I. Stevanovic, "Optimized magnetic design for inductive power transfer coils," in Proc. 28th APEC, 2013, pp. 1812-1819. https://doi.org/10.1109/APEC.2013.6520541

[4] J. Cho, J. Sun, H. Kim, J. Fan, Y. Lu and S. Pan, "Coil design for 100 $\mathrm{KHz}$ and 6.78 MHz WPT system: Litz and solid wires and winding methods," 2017 IEEE International Symposium on Electromagnetic Compatibility \& Signal/Power Integrity (EMCSI), Washington, DC, 2017, pp. 803-806. https://doi.org/10.1109/ISEMC.2017.8077977

[5] W. Zhang and C. C. Mi, "Compensation Topologies of High-Power Wireless Power Transfer Systems," in IEEE Transactions on Vehicular Technology, vol. 65, no. 6, pp. 4768-4778, June 2016. https://doi.org/10.1109/TVT.2015.2454292

[6] M. Hassan Ameri, A. Y. Varjani, and M. Mohamadian, "A New Maximum Inductive Power Transmission Capacity Tracking Method," Journal of Power Electronics, November 2016, vol. 16, no. 6. pp. 22022211. https://doi.org/10.6113/JPE.2016.16.6.2202

[7] S. Nutwong, A. Sangswang and S. Naetiladdanon, "Output voltage control of the SP topology IPT system using a primary side controller," 2016 13th International Conference on Electrical Engineering/Electronics, Computer, Telecommunications and Information Technology (ECTI-CON), Chiang Mai, 2016, pp. 1-5. https://doi.org/10.1109/ECTICon.2016.7561393

[8] K. Song, Z. Li, J. Jiang and C. Zhu, "Constant Current/Voltage Charging Operation for Series-Series and Series-Parallel Compensated Wireless Power Transfer Systems Employing Primary-Side Controller," in IEEE Transactions on Power Electronics, vol. 33, no. 9, pp. 8065-8080, Sept. 2018.

[9] V. Shevchenko, O. Husev, R. Strzelecki, B. Pakhaliuk, N. Poliakov and N. Strzelecka, "Compensation Topologies in IPT Systems: Standards, Requirements, Classification, Analysis, Comparison and Application," in IEEE Access, vol. 7, pp. 120559-120580, 2019. https://doi.org/10.1109/ACCESS.2019.2937891 
[10] M. A. Houran, X. Yang, W. Chen, "Magnetically Coupled Resonance WPT: Review of Compensation Topologies, Resonator Structures with Misalignment, and EMI Diagnostics," Electronics, vol. 7, no. 11, 2018 , 296. https://doi.org/10.3390/electronics7110296

[11] H. Movagharnejad and A. Mertens, "Design metrics of compensation methods for contactless charging of electric vehicles," 2017 19th European Conference on Power Electronics and Applications (EPE'17 ECCE Europe), Warsaw, 2017, pp. P.1-P.10. https://doi.org/10.23919/EPE17ECCEEurope.2017.8099403

[12] I. Kondratenko, A. Zhyltsov and A. Bereziuk, "Electromagnetic field of the three-phase cylindrical inductor if it runs off with frequency converter in non-stationary modes," 2017 IEEE International Young Scientists Forum on Applied Physics and Engineering (YSF), Lviv, 2017, pp. 247250. https://doi.org/10.1109/YSF.2017.8126664

[13] "Electromagnetics. Electromagnetic, Electronics, Thermal and Electromechanical Simulation". [Online]. Available: https://www.ansys.com/products/electronics

[14] R. Bosshard, J. W. Kolar and B. Wunsch, "Accurate finite-element modeling and experimental verification of inductive power transfer coil design," 2014 I17 Applied Power Electronics Conference and Exposition APEC 2014, Fort Worth, TX, 2014, pp. 1648-1653. https://doi.org/10.1109/APEC.2014.6803527

[15] V. Shevchenko, O. Karlov, O. Husev, I. Kondratenko and B. Pakhaliuk, "Coil Design for Wireless Power Transfer with Series-Parallel Compensation" in Proc. of the 2019 IEEE 2nd Ukraine Conference on Electrical and Computer Engineering (UKRCON), July, 2019. https://doi.org/10.1109/UKRCON.2019.8879877

[16] H. Li, J. Li, K. Wang, W. Chen and X. Yang, "A Maximum Efficiency Point Tracking Control Scheme for Wireless Power Transfer Systems Using Magnetic Resonant Coupling," in IEEE Transactions on Power Electronics, vol. 30, no. 7, pp. 3998-4008, July 2015. https://doi.org/10.1109/TPEL.2014.2349534

[17] W. X. Zhong and S. Y. R. Hui, "Maximum energy efficiency tracking for wireless power transfer systems," IEEE Trans. Power Electron., vol. 30 no. 7, pp. 4025-4034, Jul. 2015. https://doi.org/10.1109/TPEL.2014.2351496

[18] J. Yin, D. Lin, C. Lee, and S. Y. R. Hui, “A systematic approach for load monitoring and power control in wireless power transfer systems without any direct output measurement," IEEE Trans. Power Electron., vol. 30 no. 3, pp. 1657-1667, Mar. 2015. https://doi.org/10.1109/TPEL.2014.2317183

[19] W. Zhong and S. Y. R. Hui, "Maximum Energy Efficiency Operation of Series-Series Resonant Wireless Power Transfer Systems Using On-Off Keying Modulation," in IEEE Transactions on Power Electronics, vol. 33, no. 4, pp. 3595-3603, April 2018. https://doi.org/10.1109/TPEL.2017.2709341

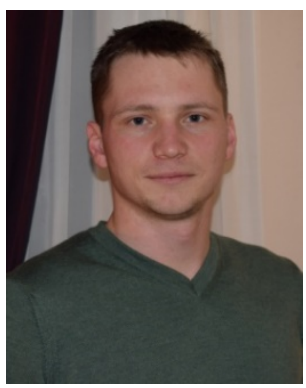

Viktor Shevchenko (S'18) was born in 1990 Ukraine. He received the B. sc. and M. sc. degrees in industrial electronics from Chernihiv National University of Technology, Chernihiv (Ukraine) in 2015 and 2017, respectively. He became $\mathrm{PhD}$ student in 2017. He is a Junior Researcher and Assistant at the Department of Biomedical Radioelectronics Apparatus and Systems, Chernihiv National University of Technology. He has several publications and patents. His area of research interests includes power electronics systems, wireless power transfer, and photovoltaic systems.

E-mail: shevaip1990@gmail.com

ORCID iD: https://orcid.org/0000-0001-6201-8693

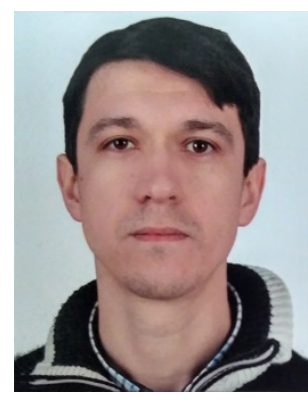

Maksym Khomenko received his B. sc. in electronics and M. sc. in electronic systems from Chernihiv State University of Technology (CSUT), Chernihiv (Ukraine) in 2003 and 2004, respectively. He obtained his Doctoral degree in electrical engineering from the National Technical University of Ukraine "Kyiv Politechnic Institute" in 2011. He became an Engineer in 2004, a Lecturer in 2008, and Associate Professor in 2012 at Chernihiv National University of Technology. From 2017 to 2018 he worked as a Research Fellow at Bonn-Rhein-Sieg University of Applied Sciences. His current research interests include intelligent control systems, artificial neural networks, signal processing, power electronics and renewable energy.

E-mail:mr.homax@gmail.com

ORCID iD: https://orcid.org/0000-0001-9084-3527

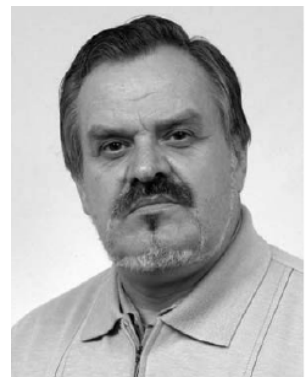

Igor Kondratenko received the $\mathrm{M}$. sc. and Dr. sc. ing. (fundamentals of electrical engineering) degrees from the National Technical University of Ukraine "Kiev Polytechnic Institute," Kiev (Ukraine) in 1978 and 1987, respectively. He is currently with the Institute of Electrodynamics of the National Academy of Science of Ukraine, Kiev, where he was an Engineer and Researcher in 1978 and has been a Principal Researcher since 2002. He received the Dr. sc. ing. degree in 2005 and, since that time, he works as the Head of the Department of Electromagnetic Systems at the same institute. His research interests include electromagnetic processes in conducting media, devices for the generation of electromagnetic forces, and inductive heating of metals.

E-mail: dep7ied@ukr.net

ORCID iD: https://orcid.org/0000-0003-1914-1383

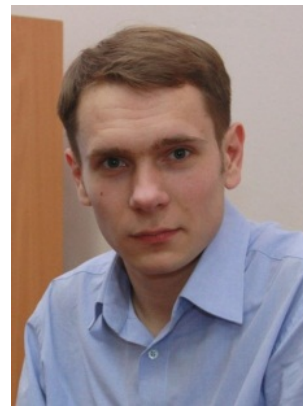

Oleksandr Husev (S'10-M'12-SM'19) received the B.sc. and M. sc. degrees in industrial electronics from Chernihiv State Technological University, Chernihiv (Ukraine) in 2007 and 2008, respectively. He defended Ph. D. thesis at the Institute of Electrodynamics of the National Academy of Science of Ukraine in 2012. He is a Senior Researcher at the Department of Electrical Power Engineering and Mechatronics, TalTech University and Associate Professor at the Department of Biomedical Radioelectronics Apparatus and Systems, Chernihiv National University of Technology. He has over 100 publications and is the holder of several patents. His research interests lie in power electronics systems, design of novel topologies, control systems based on a wide range of algorithms, including modelling, design, and simulation, applied design of power converters and control systems and application, stability investigation

E-mail: oleksandr.husev@gmail.com

ORCID iD: https://orcid.org/0000-0001-7810-457X

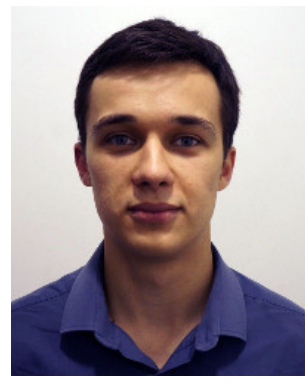

Bohdan Pakhaliuk (S'18) received the B. sc. and M. sc. degrees in industrial electronics from Chernihiv National University of Technology, Chernihiv (Ukraine) in 2016 and 2018, respectively. $\mathrm{He}$ is a $\mathrm{Ph}$. D. student of double postgraduate study at Gdansk University of Technology and Chernihiv National University of Technology. He is a Junior Researcher at the Department of Biomedical Radioelectronics Apparatus and Systems, Chernihiv National University of Technology. His research interests lie in design and control converters for wireless

power transfer applications.

E-mail: bohdan.pakhaliuk@gmail.com

ORCID iD: https://orcid.org/0000-0002-2303-5084 